\title{
SPOONERISMS: THE STRUCTURE OF ERRORS IN THE SERIAL ORDER OF SPEECH
}

\author{
Donald G. MACKaY* \\ Psychology Department, University of California, Los Angeles, California 90024, U.S.A.
}

(Received 16 September 1969)

\begin{abstract}
Spoonerisms are defined as involuntary rearrangements of elements in the serial order of speech, as when waste the term is produced as taste the werm. An analysis of 124 Spoonerisms in the natural speech of Germans showed that:

1. Identical phonemes usually preceded (or followed) the reversed phonemes.

2. Reversals preceding identical phonemes were as common as reversals following identical phonemes.

3. Reversed phonemes usually had similar articulatory form, i.e. voicing, nasality, openness, and syllabic position were usually similar. But the place of articulation of reversed phonemes differed more frequently than would be expected by chance.

Without serious revision chain-association theories appeared incapable of explaining these and other aspects of Spoonerisms. An alternative theory of serial order was proposed which had potential application not only to the pronunciation of words, but to the syntax of other forms of behavior and perception as well.
\end{abstract}

\section{INTRODUCTION}

SPOONERISMS are defined as involuntary reversals in the serial order of speech as in [1] and [2] from GoLDSTEIN [1].

$$
\begin{aligned}
& \text { overinflated state } \rightarrow \text { overinstated flate } \dagger \\
& \text { pus pocket } \rightarrow \text { pos pucket }
\end{aligned}
$$

Curiously enough the Spoonerism is named after a man who rarely made Spoonerisms as dictionaries define them. A recent study indicates that Spooner's Spoonerisms were rather carefully planned-high level humor rather than unintentional error [2]. This of course means that Spooner's original reversals (e.g. [3] and [4]) probably tell us little about the normal mechanisms of speech production.

You've missed my history lectures $\rightarrow$ You've hissed my mystery lectures

Pardon me, madam, this pew is occupied. May I show you to a seat?

$\rightarrow$ Mardon me, padam, this pie is occupewed. May I sew you to a sheet?

But involuntary reversals do occur and, since LASHLEY's famous paper in 1951, attention has been focused on the challenge of Spoonerisms to theories of the serial order of behavior. Involuntary Spoonerisms are crucial facts to be explained in theories of serial behavior in the same sense that illusions are crucial for theories of perception [5].

In the present study we analyzed a large collection of Spoonerisms in the hope of gaining some insight into mechanisms that might underlie the serial ordering of behaviour.

* This work was supported in part by an MIT intramural fellowship, UCLA Grant 2428, and USPHS Grant 16668-01. The author thanks $H$. Schulze for his help in tianslating Meringer.

† The arrow in these formulae is synonymous with "was spoken as". 
Our approach was similar to that recommended by John Hughlings Jackson: to infer the properties of a complex and unobservable system from its transitory malfunctions, working backwards from its output rather than forwards from its input. Insofar as the malfunctions in the real system are not the result of random disturbances, results of such an approach could be of interest to linguists, psychologists, speech pathologists, and neurophysiologists.

More specific questions that motivated the study were these: What factors contribute to Spoonerisms? For example, do repeated phonemes frequently precede reversed phonemes as suggested in a recent theory of serial order in speech [6]? Are reversed phonemes usually similar in articulatory form? Do reversed phonemes obey a syllableplace law (i.e. originate in identical syllabic positions)? Do reversed phonemes usually occur in the initial syllable of words? Are reversed phonemes usually close together or widely separated? How are phonemes intervening between reversed phonemes correctly produced? What mechanisms underlie the occurrence of Spoonerisms, and specifically, how do Spoonerisms bear on the general problem of serial order in behaviour and perception?

\section{DATA}

Numerous collections of Spoonerisms have already been published $[7-9,1]$. But strict criteria should be adopted for evaluating any given collection of errros:

\section{Extensiveness}

How many examples are available? As BAWDEN [8] points out, conclusions from errors in speech only become possible when the errors are collected in laige numbers. Inductive generalizations from a small number of cases are out of the question.

Context

The entire sentential context in which an error occurs should be reported.

Validity

Care must be taken to ensure that a speech error is really a speech error and not an educational deficiency. Similarly, the possibility that an error was intentional or planned must be ruled out (e.g. by asking the individual what caused his error).

Accuracy

The help of the individual who made the error should also be elicited to ensure the error is accurately recorded.

\section{Documentation}

The name of the individual making the error should be provided with his age, state of fatigue, etc., as well as his introspections concerning the cause of his error.

\section{Non-selective report}

The possibility of selective recording or reporting of errors should be ruled out.

By these criteria, Meringer's corpus is far superior to all other collections. His two books [7, 8] include an estimated 4400 errors in natural speech (124 of which were involuntary Spoonerisms). For every error he heard, MERINGER noted the date of birth and name of the speaker, most of whom were professors at the University of Vienna, and whenever the speaker's educational background was slightly less extensive than this, MERnNGER reported this deficit. He also recorded the time of day the error occurred, the state of fatigue of the speaker, his estimated rate of speech at the time of the error, and the speaker's intuitions concerning the cause of his error. Moreover, the errors occured in conversational speech rather than in prepared speeches, the1 eby further reducing the possibility that the speakers had planned or fabricated the errors. MERINGER also reported the exact linguistic context in which each error occurred, recording verbatim what the speaker had just said and what he was about to say, and when relevant, what the speaker had just heard said or saw written!

Finally, the possibility that MERINGER was selective in his recording, hearing, or reporting of errors seems unlikely. First, even though slips of the tongue might occur too frequently to permit noting every one 
of them [8], MERINGER at least attempted to be completely thorough. As an interesting comment on Meringer's success in this regard, StuRTEvant [4] reports that Meringer was so exhaustive in his collection of errors and interrogation of speakers, that as a result he became very unpopular among his acquaintances at the University of Vienna. Second, MerINGER was careful to note the possibility of misrecording an error when the conditions for either hearing the error, or interrogating the speaker were less than optimal. And third, MERINGER himself was less interested in confirming any theories of his own than in classifying speech errors, much like a Linnean zoologist would classify a new species of insect he discovered. Finally, MERINGER called special attention to errors falling outside of pre-established classifications, so that the possibility of observer selectivity or distortion in collecting the errors seems remote.

We therefore based our analyses almost exclusively on MERINGER's data, using other sources (e.g. BAwDEn [8]) as a supplement to MERINGER's corpus.

\section{NULL HYPOTHESES}

For each factor we examined we determined a Null Hypothesis (the assumption that the factor played only a chance role in the occurrence of Spoonerisms). These Null Hypotheses were based on the frequency of the factor under consideration in speech not containing Spoonerisms. Of course we wanted the natural speech to be as representative of MERINGer's speakers as possible. But since MERINGER only published the errors of his speakers, we corrected the errors in sentences containing semantic and syntactic anomalies (as in [5]) to provide a corpus of natural speech.

Es macht den Eindruck $\rightarrow$ Es hat den Eindruck

Because of the difficulty in constructing null hypotheses for semantic factors, we were limited to the analysis of phonetic factors. Thus the possibility of a semantic factor in errors such as [6] was noted,

but was overlooked in our analyses.

$$
\text { Freimaurer } \rightarrow \text { Fraumeirer }
$$

\section{(a) Repeated phoneme hypothesis}

Chain association models of speech production predict that repeated phonemes should frequently precede the reversed phonemes in Spoonerisms [6]. For example, ABRACADABRA might be produced as ABRADACABRA in this model, all other factors being equal (see Fig. 1).

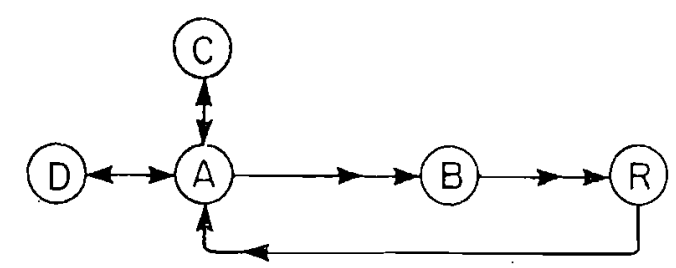

\section{ABRACADABRA}

FIG. 1. The Chain Association Hypothesis (after WICKELGREN, 1969). WiCKELGREN's context sensitive chain association differs from this model in that allophones are represented and not phonemes. But the principle of serial order is unidirectional associative bonds as represented here.

As a test of this prediction we analyzed the frequency with which identical phonemes preceded the reversed phonemes in MERINGER's corpus. Two analyses were carried out. In the first analysis, \#, the space between words, was counted as a phoneme, as demanded 
by WICKELGREN's theory. Thus examples such as [7-11] would fit WiCKELGREN's model with this analysis (repeated phonemes underlined).

$$
\begin{aligned}
& \text { damit \# bin } \rightarrow \text { damin \# bit } \\
& \text { Cavalerie } \rightarrow \text { Calaverie } \\
& \text { Kolonial } \rightarrow \text { Konolial } \\
& \text { njchtnutzig } \rightarrow \text { nuchtnitzig } \\
& \text { \#- Mond \# und \# Sonne } \rightarrow \text { Sond \# und \# Monne }
\end{aligned}
$$

A second analysis was carried out not using \# as a phoneme. Then the chance probability of phoneme repetition prior to reversed consonants was calculated on the assumption that any pair of phonemes in natural speech can be reversed. Here as well, phoneme repetition was analyzed with and without counting \# as a phoneme. In order to facilitate the construction of the null hypothesis, only Spoonerisms within a word or between adjacent words were analyzed. Thus the null hypothesis was:

$$
F(R)=\frac{1 \sum_{x=1}^{z} N R_{x}(100)}{2 \sum_{x=1}^{z}\left[\left(n P_{2}\right)-i P_{2}\right]} \quad \text { (in per cent) }
$$

where $F(R)$ is the possible frequency of reversals (within or between adjacent words in the corpus of natural speech) with identical phonemes preceding the reversed phonemes; where ${ }_{n} P_{2}$ is the number of possible permutations of two phonemes in the $n$ phonemes of the words, and ${ }_{i} P_{2}$ is the number of possible permutations of identical phonemes, and $N R_{x}$ is the number of possible reversals preceded or followed by identical phonemes for word pair $X$, and $Z$ is the total number of word pairs in the corpus of natural speech.

The resulting data are shown in Table 1 . When \# was counted as a phoneme, the

Table 1. Reversals involving repeated phonemes, proactively

\begin{tabular}{lcc}
\hline & $\begin{array}{c}\text { Proactive } \\
\text { repetition }\end{array}$ & Chance \\
\hline $\begin{array}{c}\text { \# Counted as } \\
\text { phoneme }\end{array}$ & 38 & 8 \\
$\begin{array}{c}\text { \# Not counted } \\
\text { as phoneme }\end{array}$ & 24 & 4 \\
\hline
\end{tabular}

Chance is calculated from natural speech.

null hypothesis predicted that 8 per cent of reversals would be preceded by repeated phonemes, whereas in reality 38 per cent of them were. This difference was significant at the 0.001 level (Chi Square Test). Similarly when \# was not counted as a phoneme, identical phonemes preceded the reversed phonemes more frequently than would be expected by chance (see Table 1). On the surface these data appear to support WiCKELGREN's chain association theory of speech production. However, our data contradict another 
prediction of the chain association model. The model predicts that repeated phonemes should precede reversed phonemes more frequently than follow them (since associative bonds are unidirectional). In fact, however, repeated phonemes followed the reversed phonemes at least as frequently as they preceded them. Examples of such Retroactive Spoonerisms (where repeated phonemes follow the reversed phonemes) are shown in [12-14] (repeated phonemes underlined). Note that [15] exemplifies a Proactive and Retroactive Spoonerism since a repeated phoneme also precedes the reversed phonemes.

$$
\begin{aligned}
& \text { Wasserflasche } \rightarrow \text { Flasserwasche } \\
& \text { Mond und Sonne } \rightarrow \text { Sond und Monne } \\
& \text { Wachsen die Haar } \rightarrow \text { Hachsen die Waar } \\
& \text { Tiefstufe } \rightarrow \text { Tufstiefe }
\end{aligned}
$$

A comparison of the frequency of Proactive and Retroactive Spoonerisms is shown in Table 2. As can be seen there, Retroactive Spoonerisms were slightly more frequent than Proactive ones when \# was counted as a phoneme. This finding does not support the chain association prediction, especially since this analysis would bias the outcome in

Table 2. Reversals involving repeated phonemes, retroactively and proactively (see text for explanation)

\begin{tabular}{llcc}
\hline & & \multicolumn{2}{c}{ Phoneme repetition } \\
\cline { 3 - 4 } & & Proactive & Retroactive \\
\hline \# Counted as a phoneme & Data & 48 & 52 \\
& Chance & 49 & 51 \\
\# Not counted as a phoneme & Data & 38 & 62 \\
& Chance & 50 & 50 \\
\hline
\end{tabular}

Chance is calculated from natural speech.

favor of Proactive Spoonerisms if the initial phoneme of words plays a special role in Spoonerisms. For this reason a second analysis was carried out excluding \# as a phoneme. The results of this analysis are also shown in Table 2 where it can be seen that Retroactive reversals were much more common than Proactive ones. This difference was significant at the 0.05 level, by Chi Square test, a finding that directly contradicts the chain association prediction. Apparently the repeated phoneme effect operates both forwards and backwards in the serial order of speech.

Finally we combined the frequencies with which identical phonemes preceded or followed the reversed phonemes in our corpus. The resulting data are shown in Table 3. Seventy-eight per cent of the Spoonerisms were preceded or followed by repeated phonemes, whereas the chance expectation was only 14 per cent. This difference was significant at the 0.001 level.*

A similar analysis was carried out where \# space was not counted as a phoneme.

\footnotetext{
* Since two-tailed tests were used in all statistical tests in this study, this information will not be repeated.
} 
Table 3. Reversals involving repeated phonemes (in per cent)

\begin{tabular}{llcc}
\hline & & $\begin{array}{c}\text { Repeated } \\
\text { phonemes: } \\
\text { Proactive } \\
\text { or } \\
\text { Retroactive }\end{array}$ & $\begin{array}{c}\text { No } \\
\text { repeated } \\
\text { phonemes }\end{array}$ \\
\hline \# Counted as a phoneme & Data & 78 & 22 \\
\# Not counted as a phoneme & Chance & 14 & 86 \\
& Data & 47 & 53 \\
& Chance & 9 & 91 \\
\hline
\end{tabular}

Chance is calculated from natural speech (from MERINGER).

The results are shown in Table 2. Again, the transposed phonemes were surrounded by identical phonemes much more frequently than would be expected by chance.

(b) Proximity hypothesis

One theory of Spoonerisms [10] predicts that reversed phonemes will occur more closely together than would be expected by chance. This Proximity Hypothesis was separately tested for within word Spoonerisms (e.g. [16-17]) and between-word Spoonerisms (e.g. [18-19]).

$$
\begin{aligned}
& \text { Helena } \rightarrow \text { Henela } \\
& \text { Karabacek } \rightarrow \text { Barakacek } \\
& \text { Senile Demenz } \rightarrow \text { Denile Semenz } \\
& \text { Knoten in die Nase } \rightarrow \text { Knaten in die Nose }
\end{aligned}
$$

1. Within-word Spoonerisms. Proximity was analyzed in several ways. Since all of the analyses gave similar results, only the syllable analysis is presented here. Since reversed phonemes almost invariably occurred in different syllables, we let 0 represent reversed phonemes in immediately adjacent syllables, separation 1 , one intervening syllable, and so on. The average separation of reversed phonemes is shown in Fig. 2 where it can be seen that reversed phonemes occurred in adjacent syllables more frequently than in nonadjacent syllables.

However this finding is somewhat meaningless until we know the chance proximity of phoneme reversal in these words, since reversals in anything but inmediately adjacent syllables would be logically impossible if these words never exceeded two syllables in length. The null hypothesis was based on the assumption that any pair of phonemes can be reversed at any point in these words. Thus the chance probability of reversals with separation $j$ (in syllables) is:

$$
P(R j)=\frac{\sum_{i=0}^{n} S i j}{\sum_{j=0}^{n-2} \sum_{i=1}^{n} S_{i j}}
$$

where $S i j=F(l i)[i-(j+1)]$

if $i \geq j+2$,

and otherwise $S i j=0$ 


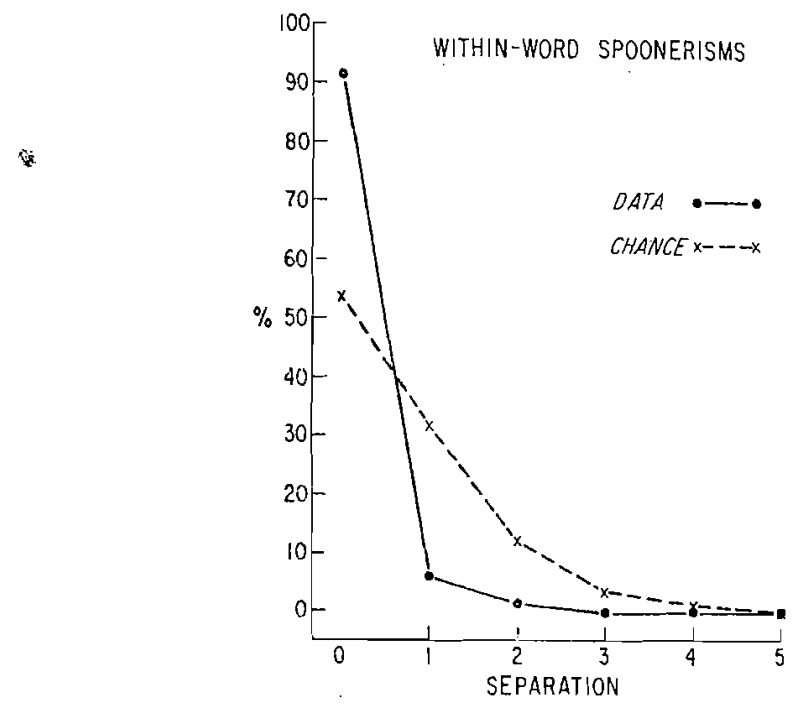

Fig. 2. The proximity (in syllables) of reversed phonemes of within-word Spoonerisms. Chance is calculated as the possible frequency of reversal in words containing the within-word Spoonerisms, assuming that reversals occur at random.

where $P(R)$ is the probability of reversals with separation $j, F(7 i)$ is the frequency of words $i$ syllables long, and $\mathrm{n}$ is the length of the longest word (in syllables). Thus by chance the expected proximity of reversed phonemes is:

$$
F(R j)=P(R j) \times 100 \quad \text { (in per cent })
$$

for each of the $j$ degrees of separation.

These expected frequencies are plotted in Fig. 2, where it can be seen that Spoonerisms occurred in adjacent syllables with greater than chance probability, and in more distant syllables with less than chance probability. Thus reversed phonemes occurred closer together than would be expected by chance. For some reason, reversed phonemes "like to be" close together.

2. Between-word reversals. The null hypothesis for determining the chance proximity of between-word reversals had to be based on the number of syllables per sentence rather than per word. The average sentence length in the corpus of natural speech was 10 syllables (based on those cases where Meringer gave the entire sentential context). Thus the chance proximity of between-word reversals is:

$$
F(R j)=\frac{\sum_{j=0}^{10} S j(100)}{10-j}
$$

where $S j=F(i)[i-(j+1)]$ as before, and $j$ is the separation in syllables. 
The data are shown in Fig. 3 where it can be seen that reversals with separation 0 and 1 occurred more frequently than would be expected by chance, but wider separations were less frequent than chance expectation. Thus the reversed phonemes in both within word and between word reversals were more closely together than would be expected by chance.

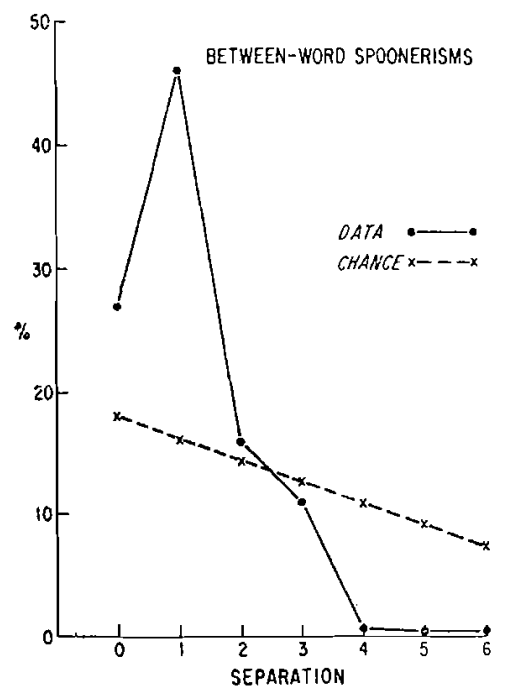

Fig. 3. The proximity (in syllables) of the reversed phonemes of between-word Spoonerisms in sentences. Chance is calculated as the possible frequency of reversals in sentences of that length, assuming that reversals occur at random.

Finally vowels and consonant reversals were compared for proximity. The data are shown in Table 4 (averaged for within and between word reversals). As can be seen, these reversed consonants tended to occur more closely together than reversed vowels.

Table 4. Proximity of reversed consonants and vowels (in phonemes)

\begin{tabular}{clcc}
\hline & & \multicolumn{2}{c}{$\begin{array}{c}\text { Separation of } \\
\text { reversed phonemes }\end{array}$} \\
\cline { 3 - 4 } & & $\begin{array}{c}\text { Within- } \\
\text { word } \\
\text { reversals }\end{array}$ & $\begin{array}{c}\text { Between- } \\
\text { word } \\
\text { reversals }\end{array}$ \\
\hline \multirow{3}{*}{ German } & Consonants & 1.1 & 3.3 \\
English & Cowels & 2.4 & 5.3 \\
& Consonants & 2.0 & 4.0 \\
\hline
\end{tabular}

\section{(c) Phonetic similarity hypothesis}

One theory of Spoonerisms (outlined in the discussion) predicts similarity in the phonetic form of reversed phonemes. One piese of evidence for this Phonetic Similarity Hypothesis is the fact that consonants and vowels were never interchanged with one 
another. Consonants were always interchanged with other consonants and vowels with other vowels.

More detailed support for the Similarity Hypothesis was obtained by comparing the similarity of single consonant reversals. Similarity was measured in terms of the number of shared distinctive features. The standard ICL distinctive feature system (as modified by WICKELGREN [11]) was used in this analysis since it was based on articulatory rather than acoustic criteria, which seemed less relevant to errors in articulation. For each distinctive feature system $j$, the similarity $S$ of reversed consonant pair $i$ was calculated as:

$$
S i=\sum_{j=1}^{4} \sum_{i=1}^{81} I_{i j}
$$

where 81 was the number of single consonant reversals, $I$ was 1 when the reversed consonants took identical values on a distinctive feature dimension, and 0 when non-identical. Thus $S$ varied from 1 (when the reversed consonants were identical in all but one distinctive feature) to 4 (when the reversed consonants were completely different). Thus the overall similarity (in per cent) was:

$$
F(S j)=\sum_{i=1}^{81} \frac{S_{i j}(100)}{81}
$$

where $F(S j)=$ is the frequency of Spoonerisms of similarity $j$.

The data are shown in Fig. 4 and indicate that most reversed consonants differed in only oue distinctive feature (56 per cent) and very few differed in all 4 distinctive features. For some reason reversed consonants "like to be similar."

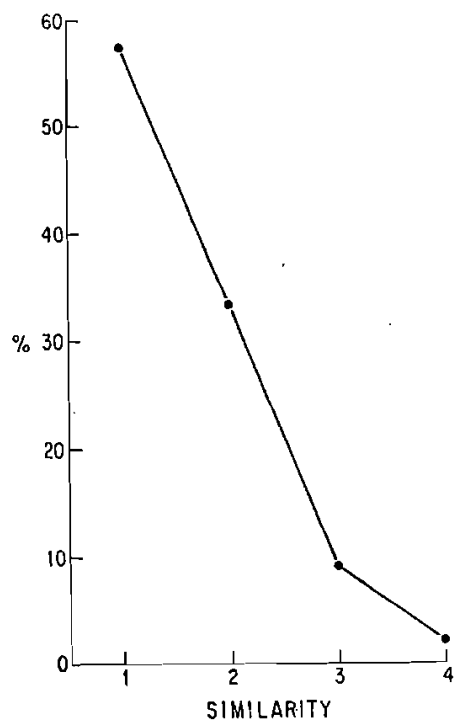

FIG. 4. Frequency of Spoonerisms as a function of similarity of the reversed phonemes (i.e. the number of different distinctive features). 
The next question was whether reversed phonemes differ in some distinctive features more than others. The similarity on each distinctive feature dimension was separately analyzed using a modification of formula 19 , namely

$$
S=\sum_{i=1}^{81} T i
$$

Chance similarity was then calculated on the assumption that consonants are reversed at random, dependent only on their frequency of occurrence in natural speech. Thus the probability of occurrence in natural speech of each of $n$ values on a distinctive feature dimension $j$ is:

$$
P j(n)=\sum_{i=1}^{24} \frac{F i(n)}{N}
$$

where $F i(n)$ is the frequency that phoneme $i$ takes feature $n$ of distinctive feature dimension $j, 24$ is the number of different consonants, and $N$ is the total sample size.

Now the probability that any two consonants taken at random from a sample of natural speech will take the same value $n$ for feature $j$ is $P j\left(S_{n}\right)$ where

$$
P j(S n)=\left[P_{j}(n)\right]^{2}
$$

Thus any pair of consonants will have the same value on feature dimensions with frequency $F_{j}(S)$, where

$$
F j(S)=\sum_{n=0}^{k-1} P n(S j)(100)
$$

where $n$ is the value on the distinctive feature dimension, and $k$ is the number of values on the dimension.

Thus the expected frequency of a different value for a distinctive feature is simply

$$
F(D)=100-F(S)
$$

The data for each of the four distinctive feature dimensions are discussed separately below.

(1) Openness, Voicing and Nasality. Consonants fall into three main classes along the openness dimension [6], stops representing openness 0 ; fricatives openness 1 ; with semivowels, laterals and aspirants representing openness 2 . About 65 per cent of the reversed consonants had the same openness value (see Table 5), whereas only 35 per cent would be expected by chance. This difference was statistically significant at the 0.05 level (Chi-Square test). Further analyses showed that this trend held for all three degrees of openness: stops were usually interchanged with other stops, fricatives with other fricatives, and semivowels with other semivowels (see Table 6). Thus the feature Openness conformed to the Similarity Hypothesis.

The same was true of Voicing and Nasality. Reversed consonants tended to have the same Voicing and Nasality more frequently than would be expected by chance (see Table 5). Thus Openness, Voicing and Nasality all fit the Similarity Hypothesis. 
Table 5. The similarity of reversed consonants: a comparison of four distinctive features, nasality, openness, voicing and place of articulation

\begin{tabular}{llcc}
\hline \multirow{2}{*}{ Feature } & & \multicolumn{2}{c}{ Similarity $(\%)$} \\
\cline { 3 - 4 } Place of Articulation & & Same & Different \\
\cline { 3 - 4 } Openness & Data & 10 & 90 \\
& Chance & 26 & 74 \\
Voicing & & & 35 \\
& Data & 65 & 35 \\
Nasality & Chance & 36 & 64 \\
& Data & 75 & 25 \\
& Chance & 52 & 48 \\
\hline
\end{tabular}

Chance was calculated on the assumption that reversed consonants will take distinctive feature values in proportion to the frequency of that value in natural speech.

Table 6. The similarity of reversed consonants on the openness dimension

\begin{tabular}{llcc}
\hline & & Same & Different \\
\hline Stops & Data & 78 & 22 \\
& Chance & 57 & 43 \\
Fricatives & & 38 & 62 \\
& Data & 38 & 81 \\
Semivowels, Laterals, & Chance & 19 & 40 \\
Aspirants & Data & 60 & 76 \\
\hline
\end{tabular}

(2) Place of articulation. Five places of articulation were examined, the extremes being 0 , a point of articulation at the lips, and 4 a point of articulation at the back of the mouth. The data are shown in Table 5 where it can be seen that place of articulation of reversed consonants differed more frequently than would be expected by chance. This difference was significant at the 0.05 level (Chi Square test). Thus place of articulation did not fit the Similarity Hypothesis.

Table 7. The similarity of reversed consonants along the place of ar ticulation dimension

\begin{tabular}{lllcc}
\hline & & \multicolumn{3}{c}{$\begin{array}{c}\text { Place of articulation of } \\
\text { second consonant }\end{array}$} \\
\cline { 3 - 5 } & & 0 & 4 & other \\
\hline Place of articulation at & Data & 10 & 54 & 36 \\
first consonant & Chance & 18 & 12 & 70 \\
& & & & 23 \\
& Data & 62 & 15 & 70 \\
\hline
\end{tabular}


A further analysis showed that front and back consonants were more frequently interchanged with each other than with consonants having other places of articulation. The data are shown in Table 7 where it can be seen that front and back consonants were interchanged with much greater than chance expectation. For some reason front and back consonants "like to be interchanged."

Finally the fact that reversed phonemes were usually similar (except for place of articulation) suggests that single features may be transposed in Spoonerisms. But in no case in our data was feature reversal the only possible explanation of an error. HocKETT [12] presents an example [29] that suggests the possibility of feature reversal (of manner but not place of articulation). FROMKIN presents

$$
\begin{aligned}
& \text { comb } \rightarrow \text { ngowp } \\
& \text { clear blue sky } \rightarrow \text { plear glue sky }
\end{aligned}
$$

a better example [30] where "the place of articulation of two phonemes may have been interchanged, but not the voicing". However these examples are extremely rare, and other explanations are possible. For example these examples might represent partial fusions of phonemes in natural speech, a frequently occurring event in studies of delayed auditory feedback. But the possibility of phoneme reversals is not eliminated even if feature reversal were demonstrable. The relevance of distinctive features no more disproves the Phonetic Unit Hypothesis for speech production than the relevance of distinctive features to speech perception disproves the importance of phonemes in speech perception.

Finally, none of Meringer's Spoonerisms violated WeLLs' [13] First Law of Lapses: "A slip of the tongue is practically always a [phonologically] possible noise." No reversal resulted in a sequence of phonemes that were inadmissable in German (e.g. initial 1k).

\section{(d) Syllabic Similarity Hypothesis}

The Syllabic Similarity Hypothesis is based on BOOMER and LAVER's [14] fifth Law of Lapses: Phonemes in initial syllabic position replace those in initial position, nuclear replace nuclear, and final replace final. The Syllabic Similarity Hypothesis was tested using HAUGEN's [15] syllabic position rules where vowels occur in three syllabic positions: initial as in IST; final as in WO; and mid-position as in MIT. Consonants occur in four possible syllabic positions: initial position, next to initial, next to final, and final positions. For example in the monosyllabic word STAND, $\mathbf{S}$ occurs in initial position, $T$ in next to initial, $N$ in next to final, and $D$ in final position. But of course for TAN by itself, $\mathrm{T}$ occurs in initial position and $\mathrm{N}$ in final position. Our question was whether reversed phonemes usually originated in identical syllabic position (determined from BRRUL [16]).

The data for consonant reversals are shown in Table 8 , where it can be seen that reversed consonants occurred in the same syllabic positions 98 per cent of the time. In only one case did the syllabic position of reversed phonemes differ and this instance ([31] below) might readily be viewed as a higher order Spoonerism of the sort LASHLEY described in typing (compare [32]). However, LASHLEY's suggested "doubling mechanism" is not the only possible explanation of these higher-order Spoonerisms (see discussion).

Plural $\rightarrow$ Prular (from MERINGer [9]

These $\rightarrow$ Thses (typing error from LASHLEY [17] 
Table 8. The similarity of syllabic positions of reversed phonemes

\begin{tabular}{llcc}
\hline & & $\begin{array}{c}\text { Same } \\
\text { syllabic } \\
\text { position }\end{array}$ & $\begin{array}{c}\text { Different } \\
\text { syllabic } \\
\text { position }\end{array}$ \\
\hline Consonants & Data & 98 & 2 \\
Vowels & Chance & 30 & 70 \\
& Data & 81 & 19 \\
& Chance & 40 & 60 \\
\hline
\end{tabular}

Also shown in Table 8, about 81 per cent of the reversed vowels originated in the same syllabic position. The data for both vowels and consonants exceeded chance expectation significantly ( 0.01 level, Chi Square test). Thus our data supported the Syllabic Similarity Hypothesis. Reversals in our corpus tended to have the same syllabic position. Several explanations of this Syllabic Similarity Phenomenon are possible. One is that the manner of producing a phoneme varies with its syllabic position; perhaps in the way STETSON [18] suggested, initial phonemes performing a syllable-releasing role, and final phonemes, a syllabic-arresting role. This interpretation would allow the tentative generalization that reversed phonemes are similar in Form of Articulation, which includes voicing, openness, nasality, and syllabic position. But reversed phonemes usually differ in Place of Articulation so that motor mechanisms underlying Form and Place of articulation must differ.

(e) The Syllabic Structure Hypothesis

Our next question was whether the nature of Spoonerisms can tell us anything about syllabic structure. Are reversals more likely in some syllabic positions than in others? The frequency of consonant reversals is shown in Table 9 as a function of syllabic position.

Table 9. Consonant reversals as a function of syllabic position

\begin{tabular}{llcccc}
\hline & & \multicolumn{4}{c}{ Consonant position } \\
\cline { 3 - 6 } & & $\begin{array}{c}\text { Syllable } \\
\text { initial }\end{array}$ & $\begin{array}{c}\text { Next to } \\
\text { initial }\end{array}$ & $\begin{array}{c}\text { Next to } \\
\text { final }\end{array}$ & Final \\
\hline $\begin{array}{l}\text { With-word } \\
\text { reversals }\end{array}$ & Data & 96 & 0 & 0 & 4 \\
Chance & 50 & 8 & 8 & 34 \\
Between-word & Data & 81 & 3 & 3 & 13 \\
reversals & Chance & 50 & 8 & 8 & 34 \\
\hline
\end{tabular}

Chance is calculated on the assumption that reversals occur at random.

As can be seen there, about 96 per cent of the within-word reversals and 81 per cent of the between-word reversals originated in initial syllabic position.

The null hypothesis was that reversals in various syllabic positions occur by chance and so reflect the frequency of these syllabic positions in natural speech. Thus, by chance, consonant reversals in position $i$ should occur with frequency,

$$
F(P i)=\frac{n_{i}(100)}{N}
$$

where $n_{i}$ is the number of consonants in position $i$, and $N$ is the total number of consonants. 
Reversals in initial syllabic position occurred significantly more often than would be expected by chance for both within and between-word reversals $(0.01$ level, Chi-Square test). This of course implies that syllable final reversals occurred significantly less frequently than would be expected by chance.

Why are final consonants so rarely reversed and initial consonants so frequently reversed? One possible explanation can be based on HockETT's [12] Syllable Structure Hypothesis. The basic assumption of this hypothesis is that consonant clusters form subgropus within the syllable, and the vowel is grouped with the final consonant or consonant cluster. Now it would be reasonable to assume that transpositions will break up the members of a subgroup less often than not. This means that under the Syllable Structure Hypothesis, syllable initial reversals should be more frequent than syllable final reversals, since final consonants form a subgroup with the vowels. Thus our data support the Syllable Structure Hypothesis. Vowel reversals should be quite rare for the same reason. Interestingly enough vowel reversals occurred about as infrequently as final consonant reversals, which further supports the Syllable Structure Hypothesis.

Furthermore, exchanges of consonant clusters (e.g. [34-35]) were quite frequent, as were exchanges of single consonants and consonant clusters (e.g. [36-38]).

$$
\begin{aligned}
& \text { Dropf krücken } \rightarrow \text { Knopf drücken } \\
& \text { kriegt er Schläg } \rightarrow \text { schliegt er Kräg } \\
& \text { vergass ganz } \rightarrow \text { verganz gass } \\
& \text { kräht kein Hahn } \rightarrow \text { häht kein } \cdot \text { Krahn } \\
& \text { Paprikaschnitzl } \rightarrow \text { Schniprikapatzl }
\end{aligned}
$$

However, reversals rarely broke up consonant clusters (as in [39]).

$$
\text { Gut und Blut } \rightarrow \text { But und Glut }
$$

which again suggests that consonant clusters form a group. Thus our data support HockET's [12] model of syllable structure.

We also examined the syllabic position of vowel reversals, using the same null hypothesis as for consonants. The data (shown in Table 10) did not exceed chance expectation, but this may have been due to our small sample size.

Table 10. Vowel reversals as a function of syllabic position

\begin{tabular}{lccc}
\hline & \multicolumn{3}{c}{ Vowel Position } \\
\cline { 2 - 4 } & $\begin{array}{r}\text { Initial } \\
\text { vowel }\end{array}$ & $\begin{array}{c}\text { Mid } \\
\text { vowel }\end{array}$ & $\begin{array}{c}\text { Final } \\
\text { vowel }\end{array}$ \\
\hline With-word reversals & 0 & 61 & 39 \\
Between-word reversals & 0 & 67 & 33 \\
Chance & 18 & 54 & 28 \\
\hline
\end{tabular}

Chance is calculated on the assumption that vowels are reversed at random. 


\section{(f) Word factors}

Does the structure of words play a role in Spoonerisms? Specifically, is the initial phoneme in words more likely to be transposed than non-initial phonemes? One of the problems in answering this question is the fact that word-initial phonemes are also syllable initial. We therefore had to determine whether syllable-initial reversals at the beginning of words were more frequent than syllable-initial reversals not at the beginning of words. The data are shown in Table 11 for both within and between-word Spoonerisms. In both cases the null hypothesis was:

$$
F(R)=\frac{\Sigma N j}{N}(100) \quad(\text { in per cent })
$$

where $F(R)$ is the frequency of reversal of the initial phoneme in a word, assuming that syllable initial phonemes are reversed at random; $N_{j}$ is the number of words in the corpus of length $j$ (in syllables), and $N$ is the total number of syllables in all of the words in the corpus.

Table 11. The frequency of consonant reversals at the beginning of wolds

\begin{tabular}{llrrrr}
\hline & & \multicolumn{3}{c}{ Syllable initial } \\
\cline { 3 - 5 } & & & $\begin{array}{c}\text { Word } \\
\text { initial }\end{array}$ & $\begin{array}{c}\text { Not word } \\
\text { initial }\end{array}$ & $\begin{array}{c}\text { Not Syllable } \\
\text { initial }\end{array}$ \\
\hline With-word reversals & Data & 33 & 63 & 4 \\
& & Chance & 15 & 35 & 50 \\
Between-word reversals & ... & Data & $\ldots .-73 \ldots$ & 8 & 19 \\
& Chance & 28 & 22 & 50 \\
\hline
\end{tabular}

As can be seen in Table 11, a word initial effect was found. For both within and between-word Spoonerisms, reversals at the beginning of words occurred more often than would be expected by chance ( 0.01 level, Chi-Square test).

Moreover, this word-initial effect was more pronounced for between-word than for within-word reversals. About 33 per cent of the syllable-initial reversals occurred in word-initial position in within-word Spoonerisms, and about 73 per cent in between-word Spoonerisms. This difference was statistically reliable, indicating a stronger effect in between than within word Spoonerisms.

Thus the initial phoneme of words stands out in the occurrence of Spoonerisms, just as it stands out in the recall of words (cf. the tip-of-the-tongue phenomenon, Brown and MCNeIL [19]).

What underlies the word-initial effect? One hypothesis is that the first phoneme of a word is grouped separately, so that the frequency of word initial reversals could be explained on the same grounds as the frequency of syllable initial reversals.

But the question now arises as to why initial phonemes of words are special. One rather interesting guess is found in the Relational Memory Hypothesis. In the Relational Memory Theory, phonemes of words are stored in an abstract, relational form, like a melody that can be played in any key. However, in such a system the first note would 
have to be separately stored (e.g. as $\mathrm{c}$ in absolute memory) if the melody is to be produced correctly.

\section{(g) Cross-language comparisons}

Our next question was whether the factors conditioning Spoonerisms are universal or common to all speakers regardless of language. As a preliminary test of this Linguistic Universal Hypothesis we compared Meringer's Spoonerisms with a corpus of Spoonerisms in English. Our question was simply whether factors such as stress and phoneme repetition play the same role in English Spoonerisms as in German ones.

The English corpus was published in 1900 by H. H. BAwDEN [8], apparently without knowledge of MERINGER's work. BAWDEN was perhaps less careful than MERINGER and in any case less explicit about his methods of data collection. Thus although exclusive reliance on BAWDEN's corpus seemed inadvisable, his data allowed an initial test of the Language Universal Hypothesis.

(1) Phoneme repetition. An analysis of proactive and retroactive phoneme repetition was carried out on the English corpus in the same way as before. The data are shown in Table 12.

Table 12. A comparison of the repeated phoneme effect in German and English with \# counted as a phoneme

\begin{tabular}{lcc}
\hline & $\begin{array}{c}\text { Repeated } \\
\text { phonemes } \\
\text { before or } \\
\text { after } \\
\text { reversal }\end{array}$ & $\begin{array}{c}\text { No } \\
\text { repeated } \\
\text { phonemes }\end{array}$ \\
\hline German & 78 & 22 \\
English & 72 & 28 \\
\hline
\end{tabular}

About 72 per cent of BAWDEN's 55 Spoonerisms involved repeated phonemes before or after the reversed phonemes, a figure very close to the 78 per cent for Spoonerisms in German. Apparently the repeated phoneme effect in Spoonerisms spans any differences between German and English as languages.

Further research on Spoonerisms in other languages is needed to test the generality of the repeated phoneme effect. However, the fragmentary data we now have on Spoonerisms in Latin, French, Greek, and Croatian, support the hypothesis that the phoneme repetition effect is language independent [see $(41-44)$ below; repeated phonemes underlined]; suggesting that this aspect of Spoonerisms may reflect a universal underlying mechanism common to all speakers.

tegmine fagi $\rightarrow$ fagmine tegi (Latin from VIRGIL [20]

cini stvoriti $\rightarrow$ cinit stvori (Croatian from VALJAVEC [21])

Pithios $\rightarrow$ Phitios (Greek from Sturtevant [4])

tous les trois $\rightarrow$ trous les tois (French from GrammoNT [22]) 
(2) Proactive and retroactive Spoonerisms. The frequency of proactive Spoonerisms (where the phonemes preceding the reversed phonemes are identical in BAwDEN's corpus is shown in Table 13 with space (\#) counted as a phoneme. As can be seen there, proactive

Table .13. The frequency of proactive and retroactive reversals in German and English (in per cent) with \# counted as a phoneme

\begin{tabular}{lcc} 
& Proactive & Retroactive \\
\hline German & 48 & 52 \\
English & 47 & 53 \\
\hline
\end{tabular}

Spoonerisms were as frequent as retroactive ones, corroborating MERINGER's data. Again it should be noted that this finding contradicts chain association theories of Spoonerisms (WICKELGREN [6]).

\section{DISCUSSION}

Recently, WICKELGREN [6] outlined a set of chain association theories for explaining the serial order of speech and behavior in general; i.e. context-free chain association; multiple-trace chain association; and context-sensitive chain association theories. He then proceeded to rule out all but one of these theories, contending that the nature of errors in speech (including Spoonerisms) supports context-sensitive chain association. However, careful examination of this theory proves it unable (without serious revision) to handle the following aspects of Spoonerisms: the retroactive repeated phoneme effect; the stress pre-entry phenomenon (discussed below); the effects of syllabic position on Spoonerisms; the phonetic similarity of the reversed phonemes; and the fact that phonemes intervening between reversed phonemes are produced without error.

Moreover context-sensitive chain association fares just as badly with other types of errors in speech such as masking (e.g. [45, 46], repeated phonenes underlined).

$$
\begin{aligned}
& \text { Schreibebrief } \rightarrow \text { Scheibebrief } \\
& \text { Finsternis } \rightarrow \text { Finternis }
\end{aligned}
$$

Thus our data called for a new approach to the problem of serial order in behavior. But first it seemed appropriate to outline the problems with which a model of Spoonerisms is faced.

\section{Preprograming}

Several sources of evidence suggest that acts stretching some distarice ahead of the ongoing output must be preprimed or partially activated before they are executed. In this regard, natural speech may resemble reading: we seen to construct phrases somewhere inside ourselves and then read them off, sometimes inaccurately (HocKETT [1.2]). That is, an entire phrase may be simultaneously displayed in a buffer system similar to that proposed by BROADBENT [23], and then read off or scanned in a unidirectional fashion not altogether unlike reading. 


\section{Prior entry}

A second problem for a model of Spoonerisms is explanation of how a later phoneme "explodes before its time" (WILLIAM JAMES [24]). This problem is handled in detail in MACKAY [10], and concerns the nature of stress or motor intensity in speech production. The basic assumption there was that the speech motor units are preprimed in proportion to their degree of stress, stressed elements taking a higher level of subthreshhold activation than unstressed ones. Priming results whenever the internal text is displayed in the buffer system, and final activation depends on scanning by a broad-band scanning device such as that shown in Fig. 5. Of course, triggering the motor units would require a period of

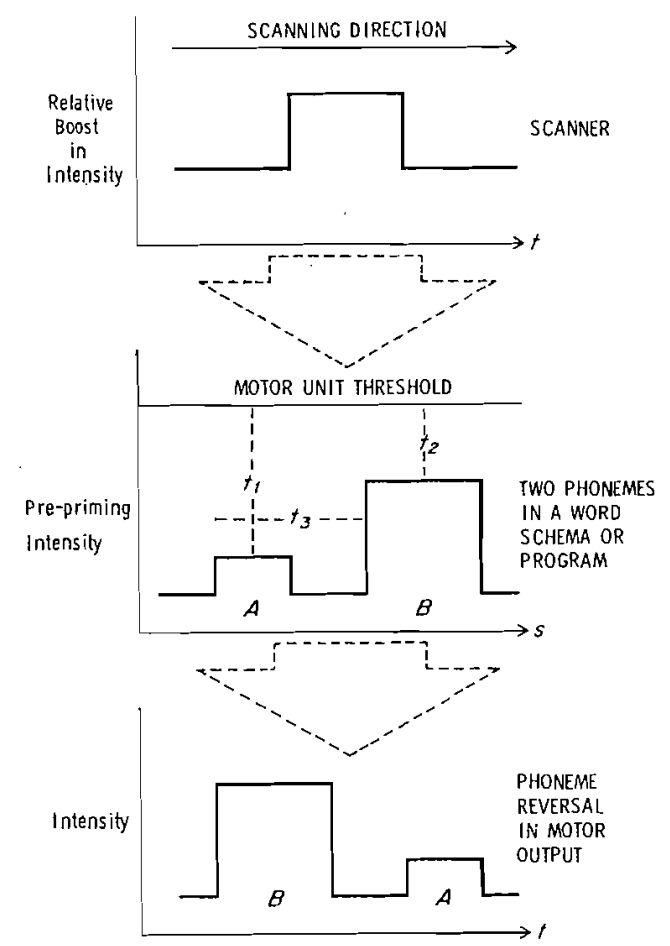

Fig. 5. An oversimplified model for explaining the stress preentry phonemenon. The model consists of three basic components: speech motor units (not shown), word engrams displayed in a buffer system where stressed segments prime the motor units to a greater extent than unstressed segments; and a scanning mechanism of the type assumed in visual systems (SPERLING [46]; see also Aaronson [47], NeISSER [48] and SteINBERg [49]). The scanning mechanism is assumed to sweep over the motor engrams in unidirectional fashion at a voluntarily controlled rate, thereby serially boosting the level of excitation of the motor units to threshold. Since the segments of the motor program are in proper serial order, the speech motor units will be activated in correct serial order if scanning is sufficiently slow. However, at rapid rates of scanning (i.e. when $t_{3}$ is short), excitation of a stressed segment of the motor program for a word may reach motor threshold sooner than a preceding unstressed segment, resulting in stress-dependent transpositions in the serial order of speech output.

The form of the scanning mechanism was arbitrarily chosen, pending further research.

Note that $t$ stands for the temporal dimension, $s$ for the spatial dimension, $t_{1}$ and $t_{2}$ for the hypothetical summation times for the two phonemes and $t_{3}$ for their temporal separation for a given rate of scanning. 
temporal summation. But the duration of temporal summation would depend on the subthreshold activation of the units, so that less time would be needed to trigger the motor units that are stressed than those that are unstressed. Parenthetically this means that stressed units will have longer duration than unstressed ones, which is in fact the case (see HeFFNer [25]). Now this model predicts prior-entry of a later phoneme when

$$
S>0
$$

where

$$
S=t_{i}-\left(t_{2}+t_{3}\right)
$$

and $t_{1}$ and $t_{z}$ are the durations of temporal summation for the first and the second phonemes (in the buffer prior to reversal), and $t_{3}$ is the time between onset of scanning these phonemes.

Now this model makes several predictions for Spoonerisms. First, the probability of phoneme reversal will be high when $t_{3}$ is short. One of the factors determining $t_{3}$ is the separation of the phonemes in the buffer. Now in this model separations of phonemes in the buffer and in the output are isometric. Thus the fact that reversed phonemes are usually close together in the output supports this model. Another factor determining $t_{3}$ is the rate of scanning which in this nodel determines the rate of speech. Most investigators (including LASHLEY [17]) agree that Spoonerisms occur most frequently during attempts to speak rapidly, thereby supporting this model. However, direct experimental data on the rate of speech question would be desirable.

The model also predicts that Spoonerisms will usually occur when $t_{2}$ is small-that is, when the second phoneme is highly stressed, which accounts for the Stree Pre-Entry Effect. Finally, it should be noted that the spatial or display aspect of the buffer system is irrelevant to the mathematical expression of this model (formula [47]) and is only a simple way of formulating the problem. The validity of this model does not depend on a spatial display within the brain.

\section{The Segmentaion Problem}

What are the units in speech production? The phrase is probably one of the units, since errors rarely transcend phrase boundaries (BOOMER and LAVER [14]). In the present study the reversed phonemes always originated in the same phrase, which further suggests that the buffer system displays no more than one phrase at a time. The syllable must be another unit since reversed phonemes tend to maintain the same syllabic position. However, syllables cannot be the "most basic" unit in speech production as KozHEvNIKov and CHISTOVICH [26] and others have suggested. The fact that in Spoonerisms a unit smaller than the syllable crosses syllable boundaries, suggests the existence of smaller units. The question now arises as to whether phonemes are a unit in this hierachy, a hotly debated question in present-day linguistics. Perhaps LashLey has advanced the best evidence for believing the phoneme to be a unit in speech production, namely, the fact that everyone (including children) can voluntarily reverse phonemes with considerable ease. Everyone can speak in ig-Pay atin-Lay. The next logical unit in the hierarchy would be the distinctive feature, but even these units should be viewed as highly abstract, and quite removed from the final motor acts. However, assuming both phonemic (and distinctive feature) units raises two additional problems. 


\section{The Coarticulation Problem}

The essence of the Coarticulation Problem is that even though we "perceive" phonemes in connected speech which can be recognized as the same in various contexts, they are not the same. Phoneticians have been unable to discover invariance in the acoustic signal, in the vocal tract configuration or in the low level neuromuscular activity for the same phoneme in different phonetic contexts $[27,28,30,31]$. Moreover [26] recent evidence suggests that both earlier and later contexts play a role in coarticulation [32]. This suggests that phonemes are modified to fit both prior and subsequent contexts.

\section{The Prior Position Phenomenon}

The fact that movement patterns depend on their position of origin constitutes the Prior Position Problem. Specifically if one pattern of movement causes some part of the body to move from A to B, a radically different movement pattern $Y$ may be required to move the same body part to the same position $B$ from a different prior position $\mathrm{C}$. For example one direction of muscular action is needed to produce the $i$ following $n g$ in SINGING but the opposite direction of movement for producing $i$ following $t$ in SITTING. Thus the muscular pattern for producing $i$ is context dependent.

One solution to the Coarticulation and Prior Position Problems is to assume that the basic units in speech production are context sensitive allophones. But this solution, advanced in detail by WICKELGREN [6] runs into other difficulties. A simpler solution is that phonemes are modified to fit the context in which they occur. That is, for each adjacent phoneme pair, $\mathrm{AB}, \mathrm{A}$ is modified proactively to fit $\mathrm{B}$ and $\mathrm{B}$ is modified retroactively to fit A. This "contextual integration" assumption corresponds to the digital to analog conversion widely assumed for all motor systems [33,34]. And as we will see, this assumption proves valuable in explaining other aspects of Spoonerisms.

\section{The Similarity Problem}

Another set of problems for an adequate model of the Spoonerism is the phonetic similarity of reversed phonemes. The fact that reversed phonemes "like to be similar" suggests an interaction between them. One Interaction Hypothesis suggested in MACKAY [10] is that "Contradictory aspects of similar motor programs interact in mutually

$B$

G

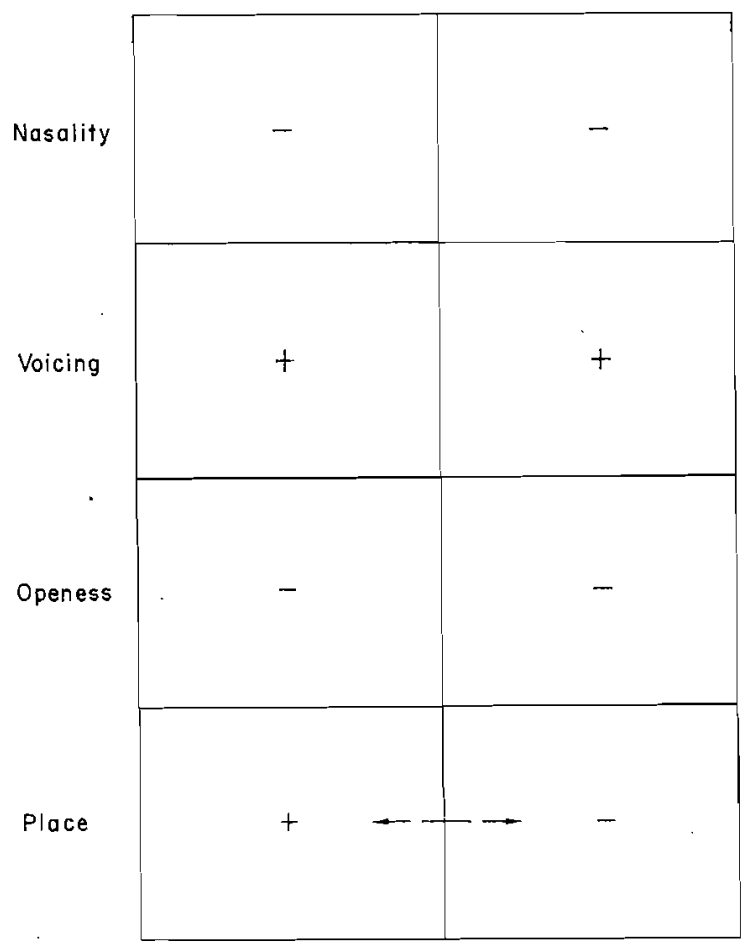

FIG. 6. The distinctive features for phonemes $B$ and $G$ with the reciprocal inhibition assumption indicated with a broken line. 
inhibitory fashion. That is when different motor commands involving the same muscles are simultaneously activated, these commands interact in mutually inhibitory fashion." Note that a similar assumption is prevalent in studies of perceptual systems (HUBEL and WIESEL [35], RatLIFF [36]). This assumption seemed logical for a number of reasons. First, reciprocal inhibition is essentially an either-or device which is exactly the sort of mechanism that would keep phonemes distinct (see Fig. 6). That is, reciprocal interaction between features, would ensure that a phoneme half way between a $p$ and an $m$ (for example) would never be produced. Second, the principle of reciprocal inhibition seems to characterize many other motor systems besides speech (see BuLLOCK [37]).

Moreover, this same reciprocal inh ibition assumption has proven essential in explaining completely different types of errors such as the omission of speech sounds (see MACKAY [10]). Finally, the reciprocal inhibition assumption proves useful in explaining several remaining problems confronting a model of Spoonerisms.

\section{The Intervening Phoneme Problem}

The fact that phonemes intervening between reversed phonemes can be correctly produced presents a major problem for the chain association models of Spoonerisms described by Wickelgren [6]. But the Intervening Phoneme Problem disappears in a model where only the reversed phonemes interact and not the intervening phonemes.

\section{The Fusion Problem}

The fusion problem is somewhat specific to scanning models of Spoonerisms: preactivation of a later act during the ongoing production of an act should result in fusion of the two. Of course short range fusion does occur and so would favor a scanning model. For example, the nasalization of $\mathrm{N}$ in STANLEY carries over into the $\mathrm{L}$, and the lips are rounded during the $\mathrm{K}$ in KWEEN (i.e. queen) in anticipation of the $W$ [25]. But fusions of phonemes in different syllables rarely, if ever, occur. The question that now arises is how a scanning mechanism can explain the transposition of more widely separated phonemes, but the fusion of these same phonemes is prevented. Again the answer may lie in a reciprocal inhibitory mechanism that prevents the simultaneous execution of different commands for the same muscles. A scanning model predicts short-range fusions whenever a muscle is not otherwise in use: that is, an articulator will perseverate or anticipate a position unless otherwise engaged according to this model. Further research is needed to test this view of short-range fusions.

\section{The Post-Entry Problem}

The next problem facing a model of Spoonerisms is how the earlier phoneme gets to be produced later. If some inhibitory mechanism blocks an earlier phoneme, some excitatory mechanism must release this inhibition and cause the subsequent production of this phoneme. Exactly such a property is built into reciprocal inhibitory mechanisms. After one of the components of a reciprocal inhibitory system is activated, the other component becomes hyperexcited and this rebound in excitability is sometimes sufficient to influence behavior [38]. Thus rebound after-discharge due to inhibitory interaction between similar phonemes may cause post-entry of the earlier phoneme in Spoonerisms.

\section{Positional specification}

A major question for scanning models is how pre-entry and post-entry occur in appropriate places. This problem is solved with the contextual-integration assumption. Consider the reversal in [48]. 


\section{Kutschkasten $\rightarrow$ Kustkatschen}

This is rather a special example, since the phonemes $s c h$ and $s$ do not simply exchange places with each other. Rather they maintain their position relative to the repeated $t$ : the $s c h$ follows $t$ before and after reversal, and the $s$ precedes $t$ before and after reversal.

Why do these phonemes maintain their position relative to a repeated phoneme rather than simply exchanging places? One answer is that the form and position of phonemes in the final output is relationally determined as suggested in the ContextualIntegration Hypothesis discussed earlier. Thus in [48] the $s$ must be proactively integrated with $t$ and the $s c h$ must be retroactively integrated with $t$ before being produced. Thus pre-entry of $s c h$ occurs exactly before $t$, and post-entry of $s$ occurs exactly after $t$, rather than exchanging places.

\section{The repeated phoneme effect}

The final problem for a model of Spoonerisms is the repeated phoneme effect. Now under the contextual integration assumption the repeated phoneme before or after the reversed phonemes acts as a sort of pivot: in retroactive Spoonerisms the reversed phonemes are both retroactively integrated with the same (pivot) phoneme; and in proactive Spoonerisms the reversed phonemes are both proactively integrated with the same (pivot) phoneme. The problem is that when the pivot is repeated, phonemes may maintain their position relative to the wrong pivot.

Serial order in perception. As LASHLEY pointed out in 1951, motor and perceptual processes have too much in common to depend on wholly different mechanisms. This being the case, analogies between motor errors and illusions in sense perception might provide fruitful hypotheses for further research. Consider the following problem in the serial order of visual perception. When two visual stimuli of similar form are presented in succession, a dim one first, and a very intense one second, the second will seem to occur before the first for certain spatio-temporal relations between the two stimuli-a phenomenon known as Phi Reversal [39].

Overlooking for now the concomitant apparent movement in Phi Reversal [40], Spoonerisms and Phi Reversal seem to obey analogous principles. Consider first the relation of Phi Reversal to differences in intensity of the reversed stimuli:

$$
P(R)=K_{1} d
$$

where $P(R)$ is the probability of reversal and $d=i_{2}-i_{1}$ where $i_{1}$ and $i_{2}$ are the intensities of the first and second stimuli respectively, and $K_{1}$ is a proportionality constant.

Now consider motor intensity in speech as analogous to input intensity in perceptual systems. By analogy the probability of Spoonerism $P(S)$ should be

$$
P(S)=K_{2} d_{2}
$$

where $d_{2}=S_{2}-S_{1}$ and $S_{1}$ and $S_{2}$ are the intensities of the first and second phonemes that become reversed in a word. Unpublished data confirm this prediction. The first phoneme (prior to reversal) is usually unstressed, and the second stressed or intense.

Next consider the form of the reversed stimuli. Several investigators have shown that Phi phenomena depend on similarity in the form of the successive stimuli [41, 42]. By analogy we would expect the reversed phonemes in Spoonerisms to be similar, as indeed we have found. 
Moreover similarity for certain aspects of the form of the stimuli is more important than for others in Phi Reversal. For example, color of the two stimuli can be varied greatly without effecting Phi reversal [39], but quite the opposite is true for stimulus size and duration: By analogy we would expect similarity of some features of phonemes to be more important than others in Spoonerisms, which seems to be the case. Of course this does not explain why the Place of Articulation of reversed phonemes usually differs, but the Form of Articulation usually remains the same in Spoonerisms.

Next consider the perception of forms interposed between stimuli involved in Phi phenomena. Kolers [43] showed that Phi phenomena failed to interfere with the perception of such intervening forms. By analogy we would expect no interference with the production of phonemes intervening between transposed phonemes in Spoonerisms, and indeed this appears to be the case, even with a large number of intervening phonemes as in (51)

Wenn er geritten ist auf der Rosinante $\rightarrow$ Wenn er gerissen ist auf der Rotinante

Finally, the proximal or phenomenal rather than distal or retinal separation is relevant to the occurrence of Phi phenomena [44]. Similarly, the phenomenal separation of words may be more relevant to Spoonerisms than the distal separation. For example, liar in in sentence [52] is phenomenally closer to boy than man, despite its distal proximity.

The boy who saw the man is a liar.

The question of phenomenal vs. distal proximity in speech errors deserves further investigation.

However, it is apparent that several aspects of the problem of serial order in perception and speech are similar at least in principle. In fact, our model of Spoonerisms is formally identical to KORTE's [39] model of the Phi Reversal. That is, in Phi Reversal,

$$
P(R)=\frac{I t}{s} \times K_{8}
$$

Here $K_{8}$ is some constant, $I$ is the intensity of the stimuli, $t$ is the time between onset of the two stimuli, and $s$ is the distance between them.

Now Korte showed that:

$$
\begin{aligned}
& I=d K_{9} \text { where } \\
& d=i_{2}-i_{1}
\end{aligned}
$$

so that when these expressions are translated into time measures in a proximal (central) scanning system, we find

$$
\begin{aligned}
& s=t_{3} \\
& t=t_{3}, \text { and } \\
& d=t_{2}+t_{3}-t_{1}
\end{aligned}
$$


so that (53) becomes

$$
\begin{aligned}
P(R)=\frac{\mathrm{d} t}{s} & =\left[K_{9}\left(t_{2}+t_{3}-t_{1}\right)\right] K_{8} \\
& =\left[t_{2}+t_{3}-t_{1}\right] K_{10}
\end{aligned}
$$

which is identical to formula 47 for Spoonerisms. However, the linitations of analogies should be emphasized. No matter how fine the grain of similarity, analogies are merely descriptive. Explanation of either Spoonerisms or Phi Reversals remains as much a mystery now as before the analogy. Nevertheless, analogies allow the hope that a model for one of the analogous phenomena will also explain the other: i.e. that a completely adequate explanation of Spoonerisms would serve as a model for research into perceptual reversals.

\section{Questions for further research}

The questions raised by the present research are perhaps as numerous as those answered. For example, where does contextual integration of phonemes occur-before the buffer display or after? If the buffer system is as LASHLEY [17] suggested, a flexible system where the order of elements can be voluntarily adjusted, a model of speech production would be simplified if the buffer display preceded and fed into the contextual integration level. One reason for this is the ease with which we can switch the order of phonemes around, as in ig-Pay atin-Lay where PAY involves a different modification of $P$ than PIG. Another reason why the buffer display should come first is that contextual integration requires specification of the order of phonemes which the buffer gives. Thus the buffer provides information needed by the Contextual Integration Level.

A second question concerns the nature of the scanning device. What is its bandwidth, i.e. how many elements does it normally cover at any point in time? What is its shape? Is it symmetrical as shown in Fig. 5, or is it skewed?

Another set of questions relates to the buffer system. How much is specified in the buffer system? In the present model, for example, duration of phonemes is left unspecified, but phonemes, syllables and stress are marked. In what form are the units in the buffer specified? Are articulatory goals or targets represented in the buffer rather than phonemes? Is stress independent of the elements that are stressed? How are syllables coded - in abstract form independent of the phonetic elements comprising them? That is, at some level in the system, the syllables of words might be represented abstractly as, for example, $\mathrm{C}_{1} \mathrm{~V}_{1} \mathrm{C}_{2}$, with a set of rules such as $\mathrm{C}_{1} \rightarrow \mathrm{T}, \mathrm{V}_{1} \rightarrow \mathrm{A}$, and $\mathrm{C}_{2} \rightarrow \mathrm{N}$. This being the case, a new factor may play a role on the occurrence of Spoonerisms. The search for $\mathrm{C}_{1} \rightarrow \mathrm{T}$ could turn up a highly similar and partially activated phoneme (e.g. D) due to occur later in a preprogramed sequence such as TANDEM. This similar phoneme could be erroneously selected giving DANTEM. Moreover, a similar factor could be involved at the syntactic level. For example, abstract syntactic forms may be ordered in concatenative fashion, e.g. $\mathrm{D}+\mathrm{N}$ with a set of rules such as $\mathrm{D} \rightarrow$ the, and $\mathrm{N} \rightarrow$ Boy. Thus, when similar nouns appear together in the context of a sequence, e.g. $N_{1} \rightarrow$ Spiel, $N_{2} \rightarrow$ Seele, then errors in the serial order of words as in (60) would be expected.

die Seele des Spiels $\rightarrow$ die Spiele des Seels (from MrRINGer and MAYer [7]) 
It should be emphasized that this higher-level explanation of Spoonerisms in no way contradicts the lower-level mechanisms proposed earlier. Several different types of mechanisms may converge to produce Spoonerisms.

The final question for further research is whether the mechanisms for serial order are similar in all motor systems? For example, do errors in the serial order of typing obey the same laws as Spoonerisms? (see MacNeILAGe [45]).

\section{SUMMARY AND CONCLUSION}

Analysis of 179 Spoonerisms in German and English revealed the following facts:

1. Repeated phonemes usually occurred before and after the reversed phonemes.

2. Reversals before repeated phonemes were as common as reversals after repeated phonemes, contradicting chain association theories.

3. The syllabic position of reversed phonemes was almost invariably identical,

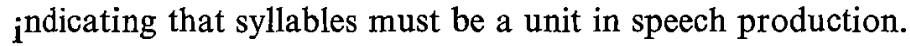

4. Consonants in the initial position of syllables were more frequently reversed than would be expected by chance. This supported Hocket's Syllable Structure Hypothesis.

5. Significantly more reversals involved the initial phoneme of words than would be expected by chance, indicating a lexical factor in Spoonerisms.

6. Distinctive features of reversed phonemes were usually similar except for place of articulation which differed more frequently than would be expected by chance. This suggested the possibility of two distinct types of mechanism in speech production: one for Form of Articulation, including voicing, nasality, and openness, and another for Place of Articulation.

7. Consonants were more frequently transposed than vowels.

8. Reversed phonemes occurred closer together in words and sentences than could be expected by chance.

9. Effects of the above factors on Spoonerisms in German and English were shown to be quantitatively similar. These factors were also noted in Spoonerisms in Latin, Croatian, Greek and French, suggesting that phoneme reversals may result from universal, underlying mechanisms common to all speakers.

10. No support was found for chain association explanations of Spoonerisms. Even the most sophisticated chain association theory was incompatible with most of the above facts.

11. Analogies between Spoonerisms and temporal reversals in sensory perception were explored.

12. At least four basic assumptions seemed necessary for adequate explanations of Spoonerisms.

Assumption 1. $P(R)=\left(t_{2}+t_{3}-t_{1}\right) K$, where $P(R)$ is the probability of reversal, $t_{1}$ and $t_{2}$ are the hypothetical summation times for producing the first and second phonemes, and $t_{3}$ is the temporal separation of the two phonemes in a central scanning system.

Assumption 2. Both phonemes and syllables are units in a whole hierarchy of units in the speech production system. 
Assumption 3. Adjacent phonemes are reciprocally integrated in programming speech output. That is, for any phoneme pair, $\mathrm{AB}, \mathrm{A}$ is modified proactively to fit $\mathrm{B}$, and $\mathrm{B}$ is modified retroactively to fit $\mathrm{A}$.

Assumption 4. Contradictory aspects of similar programs in the speech production process interact in mutually inhibitory fashion.

Thus four different levels are assumed to interact on the manner shown in Fig. 7. A

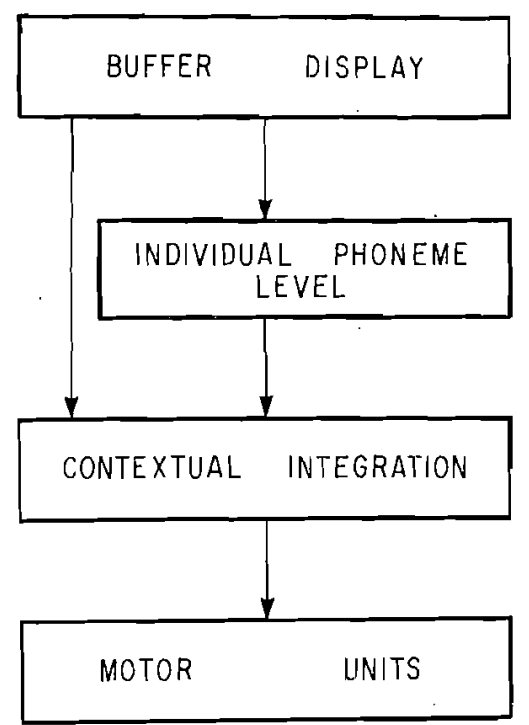

FIG. 7. An oversimplified model of speech production at the phonetic level (stress parameters not shown). Words are selected by higher-order semantic and syntactic criteria and displayed in the buffer system shown above. When this buffer system contains a word the corresponding phonemic units at the Individual Phoneme Level become partially activated, along with a set of programs for modifying these phonemes at the Contextual Integration Level. These levels in turn feed into the motor unit level, where reciprocal inhibition is assumed to occur. These motor units code the contextual variants of phonemes. But final activation of these units depends on serial scanning of the buffer system (see Fig. 5).

buffer level displays phonetic units, abstractly represented in correct serial order, with the possibility of multiple representation of the same phoneme $\left(C_{1}, C_{2}\right.$, etc.). The buffer level feeds into an individual phoneme level, partially activating a set of singly represented phonemic units through a set of correspondence rules such as $C_{1} \rightarrow B$ and $C_{2} \rightarrow D$. When $\mathrm{C}_{1}$ and $\mathrm{C}_{2}$ are similar, Spoonerisms could result from an exchange of correspondence rules so that $\mathrm{C}_{1} \rightarrow \mathrm{D}$ and $\mathrm{C}_{2} \rightarrow \mathrm{B}$, for example. The units at the Individual Phoneme level are unordered, and are activated in correct serial order through scanning of the buffer system.

Words displayed in the buffer system also partially activate a set of programs or rules for modifying phonemes to fit the phonetic context in which they occur. The rules are of the form $A \rightarrow A^{\prime}$ before $D$. Thus when $D$ is repeated, integration with $D_{2}$ may occur rather than with $D_{1}$, resulting in a Spoonerism.

The final level is the motor unit level that codes the contextual variants of phonemes (i.e. $\left.A^{\prime}\right)$. Reciprocal inhibition is assumed to occur at this level, so that prior entry of one unit may result in postentry of the other unit of a mutually inhibitory pair. 


\section{REFERENCES}

1. Goldstein, M. Some slips of the tongue. Psychol. Rep. 22, 1009-1013, 1968.

2. RobBins, R. H. The warden's wordplay: Toward a redefinition of the Spoonerism. Dalhousie Rev. 46, $457-465,1966$.

3. MacNeilage, P. F. Personal communication, 1968.

4. Sturtevant, E. H. Linguistic Science. Yale University Press, New Haven, 1947.

5. TeuBer, H. L. Handbook of Psychology III; Neuro-Physiology, Field et al. (Editors), Chap. 65, pp. 1596-1668. New York, 1960.

6. Wickelgren, W. A. Short-term memory for repeated and non-repeated items. Q. $l$. exp. Psychol. 17, $14-25,1965$.

WICKELGREN, W. A. Associative intrusions in short-term recall. J. exp. Psychol. 72, 853-858, 1966.

WICKELGREN, W. A. Context-sensitive coding, associative memory, and serial order in (speech) behavior. Psychol. Rev. 76, 1-15, 1969.

7. MERINGER, R. and MAYER, K. Versprechen und Verlesen: Eine Psychologisch-Linguistische Studie. Göschensche Verlagsbuchhandlung, Stuttgart, 1895.

8. Bawden, H. H. A study of lapses. Psychol. Monogr. 3, 1-121, 1900.

9. MERINGER, R. Aus dem Leben der Sprache: Versprechen; Kindersprache, Nachahmungstrieb. Behr's Verlag, Berlin, 1908.

10. MACKAY, D. G. Forward and backward masking in motor systems. Kybernetik 2, 57-64, 1969.

11. WiCKelgren, W. Distinctive features and errors in short-term memory for English consonants. $J$. acoust. Soc. Amer. 39, 388-398, 1966.

12. HockeTT, C. F. Where the tongue slips, there slip I. In To Honor Roman Jakobson. Mouton, The Hague, 1967.

13. Wells, F, L. Linguistic Lapses. Science Press, New York 1906.

14. Boomer, D. S. and Laver, J. D. Slips of the tongue. Br.J. Disorders Communication. 3, 1-12, 1968.

15. Haugen, E. The syllable in linguistic description. In For Roman Jakobson, 213-221. Mouton, Paris, 1956.

16. BrevL, K. (Editor) German and English Dictionary. Heath, Boston, 1906.

17. LASHLEY, K. S. The problem of serial order in behavior. In Cerebral Mechanisms in Behavior: The Hixon Symposium, L. A. JefFeress (Editor). Wiley, New York, 1951.

18. STËTson, R. H. Motor Phonetics: A Study of speech movements in action. North-Holland, Amsterdam, 1951.

19. Brown, R. and MCNeIL, D. The tip of the tongue phenomenon. J. verb. Learn. verb. Behav. 5, 325-337, 1966.

20. VIRGIL, Ekloge, 26 B.C. in MERINGER [9].

21. ValuaVeC, M. Stari pici hrvatski. Zengger, 1862.

22. Grammont, in Meringer and Mayer [7].

23. Broadbent, D. E. Perception and Communication. Pergamon Press, Oxford, 1958.

24. James, W. The Principles of Psychology. Holt, New York, 1890.

25. Hefrener, R. M. S. General Phonetics. University of Wisconsin Press, Madison, 1964.

26. Kozhevnikov, V. A. and Chistovich, L. A. Speech: Articulation and Perception. U.S. Government Printing Office, Washington, D.C., 1966.

27. MacNeilage, P. F. and Sholes, G. N. An electromyographic Study of the tongue during vowel production. J. Speech Hear. Res. 7, 209-232, 1964.

28. Liberman, A. M., Cooper, F. S., Shankweiler, D. P. and Studdert-Kennedy, M. Perception of the speech mode. Psychol. Rev. 74, 431-61, 1967.

29. ÖHMan, S. E. G., Leanderson, R. and Pearson, A. EMG Studies of facial muscle activity in speech. III. Speech Transmission Laboratory Quarterly Progress and Status Report, Royal Institute of Technology, Stockhom, Sweden, 1966.

30. HARRIS, K. S. Behavior of the tongue in the production of some alveolar consonants. J. acoust. Soc. Am. 35, 784, 1963.

31. Fromkn, V. A. Neuromuscular specification of linguistic units. Language and Speech 1, 1170-1199, 1966.

32. MACNeILAGe, P. F. and De Clerk, J. L. On the motor control of coarticulation in CVC monosyllables. Paper presented at The 1967 Conference on Speech Communication and Processing, M.I.T., 1967.

33. RuCH, T. C. The cerebral cortex: is structure and motor functions. In Neurophysiology (2nd ed.), T. C. RuCH et al. (Editors). Saunders, Philadelphia, 1965.

34. Miller, G. A., Galanter, E. and Pribram, K. H. Plans and the Structure of Behavior. Holt, Rinehart \& Winston, New York, 1960

35. Hubel, D. H. and WIESEL, T. N. Receptive fiels, binocular interaction and functional architecture of the cat's visual cortex. J. Psychiol. 160, 106-154, 1962. 
36. RatrLiff, F. Inhibitory interaction and the detection and enhancement of contours. In Sensory Communication, W. A. RosenBlith (Editor), pp. 183-203. John Wiley, New York, 1961.

37. Bullock, T. H. Mechanisms of integration. In Bullock, T. H. and Horruge, G. A. Structure and Function in the Nervous System of Invertebrates. Freeman, London, 1965.

38. Von Holst, E. and Von St. Paul, U. On the functional organization of drives. Animal Behav. 11, $1-20,1963$.

39. KORTE, A. Kinematoskopische Untersuchungen. Z. Psychol. 72, 123-296, 1915.

40. GRAHAM, C. H. (Editor) Vision and Visual Perception. John Wiley, New York, 1966.

41. LINkE, P. Grundfragen der Wahrnehmungslehre, pp. 269-360. Reinhart, Munich, 1918.

42. KenKEl, F. Optische Täuschungen. Z. Psychol. 67, 358-449, 1913.

43. Kolers, P. A. Some differences between real and apparent visual movement. Vision Res. 3, 191-206, 1963.

44. Rock, I and Epenholz, S. Stroboscopic movement based on change of phénomenal rather than retina] location. Am.J. Psychol. 75, 193-207, 1962.

45. MACNEILAGE, P. F. Typing errors as clues to serial ordering mechanisms in language behavior. Language and Speech 7, 144-159, 1964.

46. SperLING, G. A model for visual memory tasks. Human Factors 5, 19-31, 1963.

47. Aaronson, D. Temporal factors in perception and short-term memory. Psychol. Bull. 75, 130-155, 1967.

48. NeIsSER, U. Decision-time without reaction-time: Experiments in visual scanning. Am.J. Psychol. 76, 376-385, 1963

49. STERnBERG, S. High speed scanning in human memory. Science 153, 652-654, 1966.

Résumé--Les contrepêteries sont définies comme des réarrangements involontaires des élèments dans l'ordre sériel de la parole, ainsi en est-il lorsque waste the term est émis pour taste the werm. Une analyse de 124 contrepêteries survenues spontanément chez des locuteurs de langue allemande a montré que:

1-Les phonèmes identiques précèdaient habituellement (ou suivaient) les phonèmes inversés.

2-Les inversions précèdant les phonèmes identiques étaient aussi communes que les inversions suivant les phonèmes jdentiques.

3-Les phonèmes inversés avaient habituellement des formes articulatoires similaires (voisement, nasalité, ouverture et position syllabique). Mais le lieu d'articulation des phonèmes inversés diffèrait plus fréquemment que ce que l'on pouvait l'attendre d'une distribution au hasard.

Sans importante révision, les théories de l'association en chaîne se révèlent incapables d'expliquer ces aspects (et d'autres) des contrepêteries. Une autre théorie de l'ordre sériel est proposée en raison de son application potentielle non seulement à la prononciation des mots, mais à la syntaxe des autres formes du comportement et de la perception.

Zusammenfassung-Schüttelreime werden als unwillkürliche Neuordnung der Reihenfolge des Sprechens definiert, wie es das Beispiel "waste the term" statt "taste the werm" zeigt.

Bei der Analyse von 124 Schüttelreimen in deutsch ergab sich folgendes:

1. Identische Phoneme gehen gewöhnlich umgestellten Phonemen voraus oder sie folgen ihnen.

2. Es kommt häufiger vor, daß umgestellte Phoneme identischen vorausgehen als umgekehrt.

3. Die umgestellten Phoneme besitzen gewöhnlich eine verwandte artikulatorische Form bezüglich Klang, Nasalität und Offenheit. Die Silbenstellung bleibt gewöhnlich die gleiche. Nur der Verbindungsort differierte bei den umgesteliten Phonemen häufiger als man es erwartete.

Es ist demnach unbedingt eine ernsthafte Revision der sog. Kettenassoziationstheorie notwendig, weil diese Theorie ungeeignet ist, die vorgenannten oder andere Aspekte der Schüttelreime zu erklären. Es wird deshalb eine neue theoretische Deutung der Reihenordnung vorgeschlagen, die man nicht nur für Wortaussprache verwenden kann, sondern sich auch auf Syntax und andere Ausdrucks- und Wahrnehmungsformen anwenden läßt. 